\title{
Propagação in vitro de Sacha inchi
}

\author{
In vitro propagation of Sacha inchi
}

\section{Stevan Ricardo Bordignon ${ }^{\mathrm{I}}$ Glaucia Maria Bovi Ambrosano ${ }^{\mathrm{II}}$ Paulo Hercilio Viegas Rodrigues $^{\mathrm{*}}$}

\section{- NOTA -}

\section{RESUMO}

O objetivo do presente trabalho foi avaliar in vitro a relação auxina:citocinina a fim de obter propágulos nos segmentos distintos do epicótilo e hipocótilo de sementes germinadas in vitro de Sacha inchi (Plukenetia volubilis Linneo). Os segmentos apical (A), mediano (B) e o basal (C) foram introduzidos em meio de cultivo MS, semi sólido (2,0g $L^{-1}$ Phytagel), suplementado com vitaminas de MS, sacarose $\left(30,0 \mathrm{~g} \mathrm{~L}^{-1}\right)$ e submetidos a três doses da auxina ácido indolbutírico - IBA $\left(0 ; 0,1 ; 0,5 \mathrm{mg} \mathrm{L}^{-1}\right)$, associadas a quatro doses da citocinina benzilaminopurina - BAP $(0 ; 0,1 ; 0,5$; $\left.1,0 \mathrm{mg}^{-1}\right)$, totalizando 36 tratamentos. Após nove semanas de cultivo in vitro, o segmento apical (A) apresentou formação de brotações por organogênese direta nas concentrações de 0,5 e 1,0 de BAP, associado a 0,0 e 0,1 de IBA. O emprego do cultivo in vitro é viável na produção de mudas, utilizando como explante a região apical de sementes germinadas in vitro.

Palavras-chave: óleo vegetal, ômega 3, micropropagação, Euphorbiaceae, Plukenetia volubilis, Linneo.

\section{ABSTRACT}

The aim of this study was to perform an in vitro evaluation of the auxin:cytokinine ratio in different segments of the epicotyl and hypocotyl of Sacha inchi (Plukenetia Volubilis Linneo) seeds germinated in vitro. The segments apical (A), median (B) and basal (C) were introduced into semi-solid MS culture medium (2.0g $L^{-1}$ Phytagel), supplemented with MS vitamins, sucrose $\left(30.0 \mathrm{~g} \mathrm{~L}^{-1}\right)$ and submitted to three doses of auxin indolebutyric acid - IBA $\left(0 ; 0.1 ; 0.5 \mathrm{mg} \mathrm{L}^{-1}\right)$, associated with four doses of the cytokinine benzylaminopurine - BAP ( 0 ; $\left.0.1 ; 0.5 ; 1.0 \mathrm{mg} \mathrm{L}^{-1}\right)$, totaling 36 treatments. After nine weeks of in vitro cultivation, the apical segment (A) presented shoot formation by direct organogenesis at the concentrations of 0.5 and 1.0 of BAP associated with 0.0 and 0.1 of IBA. It is feasible to use in vitro cultivation with the apical region of seeds germinated in vitro used as explants.

Key words: vegetal oil, omega 3, micropropagation, Euphorbiaceae, Plukenetia volubilis Linneo.

Conhecida pelos incas há milhares de anos, a trepadeira Plukenetia volubilis Linneo, ou mais comumente chamada de Sacha inchi, é uma Euphorbiaceae nativa da selva Amazônica, com centro de origem no Peru, Colômbia, Venezuela e Brasil. A semente é marrom escura e oval, rica em proteínas, vitamina $\mathrm{E}$, e principalmente em óleos poliinsaturados ômegas 3, 6 e 9. Essa cultura apresenta um grande potencial agro tecnológico e atualmente é largamente explorada por indústrias peruanas, na produção de seu azeite, possuindo propriedades nutraceuticas e larga utilização na indústria cosmética (CÉSPEDES, 2006). O controle de triglicérides pós-prandial foi comprovado em adultos jovens que consumiram o equivalente a $11 \mathrm{~g}$ do azeite de Pluketeia volubilis. O alto teor de ômega 3 presente no óleo, descrito por GUILLÉN et al. (2003), foi o responsável pela redução dos teores de triglicerídeos (HUAMÁN et al., 2008). No Brasil, é

${ }^{1}$ Laboratório de Cultura de Tecidos de Plantas Ornamentais, Escola Superior de Agricultura Luiz de Queiroz (ESALQ), Universidade de São Paulo (USP). Av. Pádua Dias, 11, CP 09, 13418-900, Piracicaba, SP, Brasil. E-mail: phvrodri@esalq.usp.br. *Autor para correspondência.

"Departamento de Odontologia Social, Bioestatística, Faculdade de Odontologia de Piracicaba, Universidade Estadual de Campinas (UNICAMP), Piracicaba, SP, Brasil. 
conhecido como Amendoim da Amazônia ou Amêndoa Lopo e o cultivo é limitado a uma pequena parcela no seu ambiente nativo, não dispondo de profundos estudos nem larga produção e industrialização do seu azeite. Além da alta concentração de ácido alfa linolênico (ômega 3) em suas sementes, o Amendoim da Amazônia apresenta características favoráveis ao reflorestamento e também para proteção de encostas contra a erosão, que poderá representar uma alternativa a áreas degradadas e a programas de agricultura familiar, já que a vida útil de seu cultivo é de aproximadamente 10 a 15 anos. O grande potencial agroindustrial da Plukenetia volubilis L. e a sua adaptabilidade a diferentes altitudes e ao clima subtropical justificam os ensaios desse artigo. A espécie se propaga apenas por via seminal, o que ocasiona um plantio desuniforme e dificulta a expansão das áreas de plantio (CÉSPEDES, 2006). Assim, pesquisas sobre a propagação in vitro são essenciais para o desenvolvimento da cultura que não apresenta estudos em cultura de tecidos vegetais. Diante disso, o objetivo do presente trabalho foi avaliar in vitro a relação auxina:citocinina nas partes distintas do epicótilo e hipocótilo de sementes germinadas in vitro.

Sementes de Sacha inchi, obtidas da coleção do Departamento de Produção Vegetal da Escola Superior de Agricultura Luiz de Queiroz - Universidade de São Paulo -, foram desinfetadas com solução de água e hipoclorito de sódio ( $2 \%$ de cloro ativo), na proporção de $3: 1(\mathrm{v} / \mathrm{v})$, por 30 minutos. Após o tratamento asséptico, as sementes foram lavadas (três vezes) com água destilada esterilizada, tiveram a casca quebrada e retirada, com o auxílio de um alicate, a fim de facilitar a germinação in vitro. As sementes sem casca foram submetidas à inoculação em meio de cultivo MS (MURASHIGE \& SKOOG, 1962), semi sólido (2,0g L $\mathrm{g}^{-1}$ Phytagel), suplementado com vitaminas de MS, sacarose $\left(30,0 \mathrm{~g} \mathrm{~L}^{-1}\right), \mathrm{pH}$ ajustado para 5,8, autoclavado por $20 \mathrm{~min}$ a $121^{\circ} \mathrm{C}$. Para obter plântulas com tamanho suficiente de hipocótilo, os vidros utilizados na inoculação mediam $13 \mathrm{~cm}$ (altura) x $7 \mathrm{~cm}$ (diâmetro) com volume de $40 \mathrm{~mL}$ de meio de cultivo. Foram inoculadas setenta sementes, sendo uma semente por vidro. As sementes foram incubadas à temperatura de $25^{\circ} \mathrm{C} \pm 2$, fotoperíodo de $16 \mathrm{~h}$, com intensidade luminosa de $40 \mu$ moles $\mathrm{m}^{2} \mathrm{~s}^{-1}$. As sementes germinadas atingiram de 11,0 a $13,0 \mathrm{~cm}$ de comprimento entre 25 e 30 dias de incubação. Das setenta sementes germinadas in vitro, foram selecionadas as sessenta melhores para formação dos segmentos e composição do ensaio, referente à capacidade de regeneração dos segmentos. As plântulas obtidas foram divididas em três segmentos, sendo o apical (A) formado pelo epicótilo e parte do hipocótilo, contendo a gema apical e a folha primordial, o segmento mediano formado pelo hipocótilo (B) e o segmento basal (C) compreendendo a raiz e também formada pelo hipocótilo. Os segmentos A, B e C foram equidistantes com aproximadamente $4,0 \mathrm{~cm}$ cada (Figura 1a). A capacidade de regeneração dos segmentos (A, $\mathrm{B} \mathrm{e} \mathrm{C)} \mathrm{foi} \mathrm{avaliada} \mathrm{com} \mathrm{a} \mathrm{inoculação} \mathrm{em} \mathrm{meio} \mathrm{de} \mathrm{cultivo}$ MS, semi sólido (2,0g L $\mathrm{L}^{-1}$ Phytagel), suplementado com vitaminas de $\mathrm{MS}$, sacarose $\left(30,0 \mathrm{~g} \mathrm{~L}^{-1}\right)$ e submetidos a três doses da auxina ácido indolbutírico - IBA $(0 ; 0,1$; $\left.0,5 \mathrm{mg} \mathrm{L}^{-1}\right)$ associadas quatro doses da citocinina benzilaminopurina - BAP $\left(0 ; 0,1 ; 0,5 ; 1,0 \mathrm{mg} \mathrm{L}^{-1}\right)$, totalizando 36 tratamentos. O delineamento experimental foi inteiramente casualizado com cinco repetições, sendo os fatores de estudo representados pelos segmentos em três níveis (A, B e C), IBA em três níveis $(0 ; 0,1 ; 0,5)$ e BAP em quatro níveis $(0 ; 0,1 ; 0,5$; $1,0)$. Os explantes foram subcultivados a cada três semanas, com a troca por meio de cultivo fresco em frasco de $9,0 \mathrm{~cm}$ (comprimento) x 7,0 cm (diâmetro) e avaliações quanto à formação de brotações e emissão de raízes, por nove semanas. As brotações obtidas

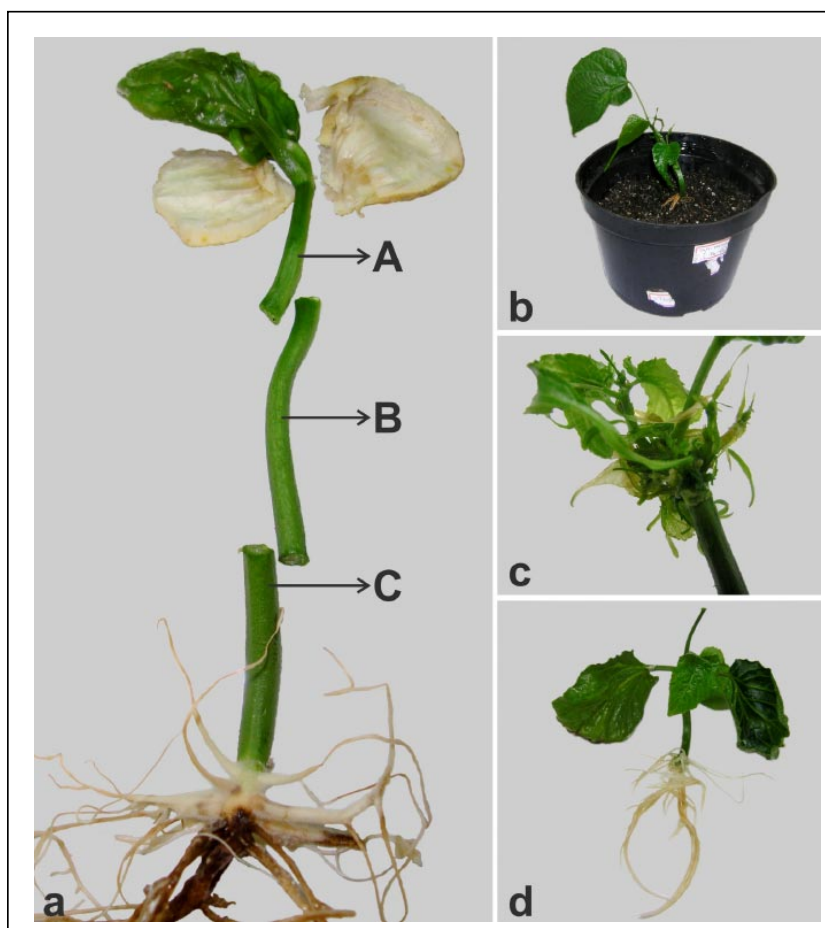

Figura 1 - (a) Plântula de Plukenetia volubilis germinada in vitro e dividida nos segmentos A, B e C; (b) Muda aclimatizada em casa de vegetação; (c) Tratamento com $1,0 \mathrm{mg} \mathrm{L}^{-1}$ de BAP e $0,0 \mathrm{mg} \mathrm{L}^{-1}$ de IBA no segmento A; (d) Plântula enraizada em $0,5 \mathrm{mg} \mathrm{L}^{-1}$ de IBA. 
foram transferidas para meio de cultivo MS, com metade da concentração de sais de MS, semi sólido $\left(2,0 \mathrm{~g} \mathrm{~L}^{-1}\right.$ Phytagel), suplementado com vitaminas de $\mathrm{MS}$, sacarose $\left(30,0 \mathrm{~g} \mathrm{~L}^{-1}\right)$ e $0,5 \mathrm{mg} \mathrm{L}^{-1}$ de IBA, em tubos de ensaio de 2,0 cm (diâmetro) x 13,0 cm (comprimento), contendo $20 \mathrm{ml}$ de meio de cultivo para elongação dos explantes e indução de raízes. As plântulas obtidas foram lavadas para retirada do excesso de meio de cultivo e transferidas para vaso pote 13 contendo substrato autoclavado e mantidas a $90 \%$ de umidade por duas semanas para aclimatização. Os dados foram analisados pelos testes de Kruskal-Wallis e Dunn (para comparar IBA e BAP) e teste de Friedman e teste não paramétrico de comparações múltiplas (para comparar segmentos). O nível de significância considerado foi de $5 \%$.

Mesmo com trabalhos reduzidos em cultura de tecidos vegetais, algumas Euphorbiaceas apresentam resposta positiva à incorporação de aditivos ao meio de cultivo. É o caso de trabalhos de suplementação dos meios de cultura com fontes exógenas de carboidratos, que favorecem a germinação in vitro de Jatropha curcas em frutos imaturos (NUNES et al., 2008). Essa suplementação é importante tanto para maximizar a taxa de germinação dessa espécie quanto para obter plântulas com elevado potencial fisiológico para serem utilizadas como fonte de explante, em estudos sobre embriogênese somática ou organogênese. Para várias espécies perenes, inclusive algumas da família Euphorbiaceae, como Jatropha podagrica (JESUS et al., 2003), foi possível estabelecer protocolos de germinação in vitro de embriões zigóticos.

No presente artigo, os segmentos estudados como explante apresentaram respostas diferenciadas quanto à combinação de auxina:citocinina a que foram submetidos. As brotações obtidas em todo ensaio foram a partir de organogênese direta, mesmo com a formação de calos em alguns tratamentos, nenhuma brotação foi originada por organogênese indireta. O segmento A apresentou maior formação de brotações quando comparado ao segmento B e ao segmento C (Tabela 1). As brotações no segmento A (Figura 1c) foram mais numerosas nas concentrações de 0,5 e 1,0mg L $\mathrm{m}^{-1}$ de BAP na ausência de IBA e na combinação de $1,0 \mathrm{mg} \mathrm{L}^{-1}$ de BAP associada a $0,1 \mathrm{mg} \mathrm{L}^{-1}$ de IBA. Na concentração máxima de auxina, não ocorreu formação de brotações, o que indica que essa relação de auxina:citocinina inibiu a formação de brotações. A relação auxina:citocinina influencia na resposta da organogênese durante a propagação in vitro. Quando ocorre dominância da concentração de auxina ou os níveis de auxina e citocinina são os mesmos, ocorre inibição da indução de brotações em plantas com dominância apical (DIMECH et al., 2007). O uso da parte apical do epicótilo como explante foi utilizado em outros gêneros como em Scotch Elm (Ulmus glabra), cana de açúcar e astromelia (MALA et al., 2005; VAZQUEZ MOLINA et al., 2005), com

Tabela 1 - Porcentagem de brotações (mediana, valor mínimo e valor máximo) nos segmentos A, B e C de Plukenetia volubilis em função das doses de BAP associada à IBA (teste Kruskal-Wallis com pós-teste Dunn $5 \%$ e Friedman).

\begin{tabular}{|c|c|c|c|c|c|c|c|c|c|c|}
\hline \multirow[t]{2}{*}{ BAP } & \multirow[t]{2}{*}{ IBA } & \multicolumn{3}{|c|}{ 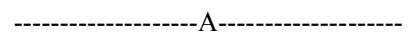 } & \multicolumn{3}{|c|}{ 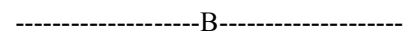 } & \multicolumn{3}{|c|}{ 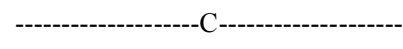 } \\
\hline & & Mediana & Mínimo & Máximo & Mediana & Mínimo & Máximo & Mediana & Mínimo & Máximo \\
\hline \multirow{3}{*}{0} & 0 & $0 \mathrm{Aa}$ & 0 & 80 & $0 \mathrm{Aa}$ & 0 & 80 & $70 \mathrm{Aa}$ & 0 & 80 \\
\hline & 0,1 & $0 \mathrm{Aa}$ & 0 & 100 & $0 \mathrm{Aa}$ & 0 & 0 & $0 \mathrm{Aa}$ & 0 & 100 \\
\hline & 0,5 & $100 \mathrm{Aa}$ & 0 & 100 & $0 \mathrm{Aa}$ & 0 & 0 & $0 \mathrm{Aa}$ & 0 & 0 \\
\hline \multirow{3}{*}{0,1} & 0 & $100 \mathrm{Aa}$ & 0 & 100 & $0 \mathrm{Aa}$ & 0 & 100 & $100 \mathrm{Aa}$ & 0 & 100 \\
\hline & 0,1 & 70Aa & 0 & 100 & $0 \mathrm{Aa}$ & 0 & 0 & $0 \mathrm{Aa}$ & 0 & 100 \\
\hline & 0,5 & $100 \mathrm{Aa}$ & 0 & 100 & $0 \mathrm{Aa}$ & 0 & 100 & $0 \mathrm{Aa}$ & 0 & 0 \\
\hline \multirow{3}{*}{0,5} & 0 & *100Aa & 100 & 100 & $0 \mathrm{Ba}$ & 0 & 40 & $0 \mathrm{ABa}$ & 0 & 90 \\
\hline & 0,1 & $100 \mathrm{Aa}$ & 0 & 100 & $0 \mathrm{Aa}$ & 0 & 0 & $0 \mathrm{Aa}$ & 0 & 0 \\
\hline & 0,5 & $50 \mathrm{Aa}$ & 0 & 100 & $0 \mathrm{Aa}$ & 0 & 0 & $0 \mathrm{Aa}$ & 0 & 0 \\
\hline \multirow{3}{*}{1,0} & 0 & *100Aa & 100 & 100 & $0 \mathrm{Ba}$ & 0 & 0 & $0 \mathrm{Ba}$ & 0 & 0 \\
\hline & 0,1 & *100Aa & 100 & 100 & $0 \mathrm{Ba}$ & 0 & 0 & $0 \mathrm{Ba}$ & 0 & 0 \\
\hline & 0,5 & $0 \mathrm{Ab}$ & 0 & 0 & $0 \mathrm{Aa}$ & 0 & 0 & $0 \mathrm{Aa}$ & 0 & 0 \\
\hline
\end{tabular}

Medianas seguidas de letras distintas (maiúsculas na horizontal e minúsculas na vertical comparando IBA dentro de cada BAP) diferem entre si $(\mathrm{P}=0,05)$. * Difere do $\mathrm{BAP}=0$ na mesma concentração de IBA e mesma parte $(\mathrm{P}=0,05)$.

$\mathrm{A}$ : segmento apical; B: segmento mediano; $\mathrm{C}$ : segmento basal.

BAP (Benzilaminopurina); IBA (Ácido Indolbutírico).

Ciência Rural, v.42, n.7, jul, 2012. 
resultado positivo para iniciar o processo de propagação in vitro, o que ocorreu no presente trabalho. $\mathrm{O}$ segmento $\mathrm{A}$, por ser uma região de crescimento, formada inclusive pela gema apical, respondeu positivamente a esta citocinina. A Plukenetia volubilis propaga-se apenas por via seminal e não assexuadamente, o processo in vitro seria uma opção a mais em seu sistema de propagação e a possibilidade de regeneração in vitro poderia sustentar um programa de melhoramento genético empregando diferentes técnicas em cultura de tecidos. O segmento $\mathrm{B}$ foi o que apresentou menor resposta às diferentes concentrações avaliadas. Apesar de ser um tecido jovem, retirado de uma plântula recém germinada in vitro, esse segmento intermediário não foi capaz de induzir brotações por organogênese direta. $\mathrm{O}$ segmento $\mathrm{C}$ apresentou maior formação de brotações em doses menores de BAP, associada a doses de 0,0 e 0,1 de IBA, não ocorrendo formação de brotações para a maior concentração de citocinina. $\mathrm{O}$ segmento $\mathrm{C}$, que compreende a região basal próxima à raiz e com acúmulo natural de auxinas, pode ter suprimido a ação da citocinina, anulando a formação de brotações nas concentrações mais elevadas de BAP. Em Scoth Elm, MALA et al. (2005) observaram, no segmento basal, concentração de auxina três vezes maior que no segmento apical cultivados in vitro. A rizogênese nos segmentos avaliados foi diretamente influenciada pela presença de BAP. Nos tratamentos sem a presença de
$\mathrm{BAP}$, ocorreu a formação de raízes nos segmentos A e $\mathrm{C}$, mas pouco expressiva em B (Tabela 2). No cultivo in vitro de mandioca, a rizogênese ocorreu tanto com auxina (ANA) como com citocinina (BAP) isoladamente (LIMA et al., 2002). No presente ensaio, com a adição de citocinina, ocorreu redução na formação de raízes, sendo nula nas concentrações mais elevadas de BAP. A rizogênese observada nos segmentos $\mathrm{A}$ e $\mathrm{C}$ reforça a possibilidade de utilização desses explantes para o estabelecimento e propagação in vitro dessa cultura. $\mathrm{A}$ resposta negativa do segmento $\mathrm{B}$ à citocinina $\mathrm{e}$ auxina, indica que este explante deve ser descartado como fonte para regeneração in vitro. A resposta das brotações ao enraizamento utilizando $0,5 \mathrm{mg} \mathrm{L}^{-1}$ de IBA foi promissora, mesmo em explantes mais finos e apresentando apenas uma raiz (Figura 1d). A fase de aclimatização, com $90 \%$ de umidade e aluminet $50 \%$ em casa de vegetação, foi o suficiente para aclimatizar o total obtido de 152 plântulas propagadas in vitro em substrato comercial BASE horticultura (Figura 1b). Desse modo, podemos concluir que o emprego da técnica de cultivo in vitro para produção de mudas de $\boldsymbol{P}$. volubilis é viável utilizando como explante a região apical de sementes germinadas in vitro. O emprego da citocinina BAP no segmento A respondeu positivamente na formação de propágulos.

Tabela 2 - Porcentagem de rizogênese (mediana, valor mínimo e valor máximo) nos segmentos A, B e C de Plukenetia volubilis em função das doses de BAP associada à IBA (teste Kruskal-Wallis com pós-teste Dunn $5 \%$ e Friedman).

\begin{tabular}{|c|c|c|c|c|c|c|c|c|c|c|}
\hline \multirow[t]{2}{*}{ BAP } & \multirow[t]{2}{*}{ IBA } & \multicolumn{3}{|c|}{ 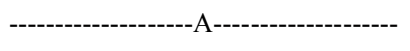 } & \multicolumn{3}{|c|}{ 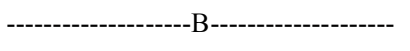 } & \multicolumn{3}{|c|}{ 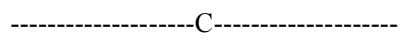 } \\
\hline & & Mediana & Mínimo & Máximo & Mediana & Mínimo & Máximo & Mediana & Mínimo & Máximo \\
\hline \multirow{4}{*}{0} & 0 & $0 \mathrm{Aa}$ & 0 & 0 & $0 \mathrm{Aa}$ & 0 & 0 & $0 \mathrm{Aa}$ & 0 & 40 \\
\hline & 0,1 & $0 \mathrm{Aa}$ & 0 & 100 & $0 \mathrm{Aa}$ & 0 & 0 & $100 \mathrm{Aa}$ & 0 & 100 \\
\hline & 0,5 & $100 \mathrm{Aa}$ & 0 & 100 & $0 \mathrm{Aa}$ & 0 & 100 & $100 \mathrm{Aa}$ & 0 & 100 \\
\hline & 0 & $0 \mathrm{Aa}$ & 0 & 0 & $0 \mathrm{Aa}$ & 0 & 100 & $0 \mathrm{Aa}$ & 0 & 100 \\
\hline \multirow[t]{3}{*}{0,1} & 0,1 & $0 \mathrm{Aa}$ & 0 & 0 & $0 \mathrm{Aa}$ & 0 & 0 & $0 \mathrm{Aa}$ & 0 & 100 \\
\hline & 0,5 & $0 \mathrm{Aa}$ & 0 & 100 & $0 \mathrm{Aa}$ & 0 & 0 & $* 0 \mathrm{Aa}$ & 0 & 0 \\
\hline & 0 & $0 \mathrm{Aa}$ & 0 & 0 & $0 \mathrm{Aa}$ & 0 & 0 & $0 \mathrm{Aa}$ & 0 & 0 \\
\hline \multirow[t]{3}{*}{0,5} & 0,1 & $0 \mathrm{Aa}$ & 0 & 0 & $0 \mathrm{Aa}$ & 0 & 0 & $0 \mathrm{Aa}$ & 0 & 0 \\
\hline & 0,5 & $0 \mathrm{Aa}$ & 0 & 0 & $0 \mathrm{Aa}$ & 0 & 70 & $* 0 \mathrm{Aa}$ & 0 & 0 \\
\hline & 0 & $0 \mathrm{Aa}$ & 0 & 0 & $0 \mathrm{Aa}$ & 0 & 0 & $0 \mathrm{Aa}$ & 0 & 0 \\
\hline \multirow[t]{2}{*}{1,0} & 0,1 & $0 \mathrm{Aa}$ & 0 & 0 & $0 \mathrm{Aa}$ & 0 & 0 & $0 \mathrm{Aa}$ & 0 & 0 \\
\hline & 0,5 & $0 \mathrm{Aa}$ & 0 & 0 & $0 \mathrm{Aa}$ & 0 & 0 & $* 0 \mathrm{Aa}$ & 0 & 0 \\
\hline
\end{tabular}

Medianas seguidas de letras distintas (maiúsculas na horizontal e minúsculas na vertical comparando IBA dentro de cada BAP) diferem entre si $(\mathrm{P}=0,05)$.

A: segmento apical; B: segmento mediano; C: segmento basal.

BAP (Benzilaminopurina); IBA (Ácido Indolbutírico).

Ciência Rural, v.42, n.7, jul, 2012. 


\section{AGRADECIMENTO}

Os autores agradecem a Fundação de Amparo à Pesquisa do Estado de São Paulo (FAPESP) (10/50335-0), pelo apoio financeiro, bolsa de IC do autor S.R Bordignon (10/177444) e a Dom Alcimar Caldas Magalhães (Diocese Alto Solimões - Tabatinga/AM).

\section{REFERÊNCIAS}

CÉSPEDES, E.I.M. Cultivo de Sacha Inchi. Tarapoto, San Martin, Peru: INIIA, Subdirección De Recursos Geneticos Y Biotecnología, 2006. $11 \mathrm{p}$.

DIMECH, A.M. et al. Micropropagation of Gymea Lily (Doryanthes excelsa Corrêa) from New South Wales, Australia. Plant Cell, Tissue and Organ Culture, v.88, p.157-165, 2007. Disponível em: <http://www.springerlink.com/content/ k0701rj1172x370g/fulltext.html>. Acesso em: 02 fev. 2007. doi: $10.1007 /$ s 1 1240-006-9188-1.

GUILLÉN, M.D. et al. Characterization of Sacha Inchi (Plukenetia volubilis L.) Oil by FTIR Spectroscopy and ${ }^{1} \mathrm{H}$ NMR. Comparison with Linseed Oil. Journal of the American Oil Chemist Society, v.80, p.755-762, 2003.
HUAMÁN, J. et al. Efecto de la Plukenetia volubilis Linneo (Sacha inchi) en la trigliceridemia posprandial. Annales Faculdad Medicina, v.69, p.263-266, 2008.

JESUS, A.M.S. et al. Cultivo in vitro de embriões zigóticos de Jatropha. Revista Ceres, v.50, p.183-189, 2003.

LIMA, G.P.P. et al. Efeito do BAP e ANA e atividade da peroxidase em mandioca (Manihot esculenta Crantz cv Mcol 22) cultivada in vitro. Revista Brasileira de Agrociência, v.8, n.2, p.127-130, 2002.

MALA, J. et al. Role of phytohormones in organogenic ability of elm multiplicated shoots. Biologia Plantarum, v.50, p.814,2005

MURASHIGE, T.; SKOOG, F. A revised medium for rapid growth and bioassays with tobacco tissue cultures. Physiologia Plantarum, v.15, p. 473-497, 1962.

NUNES, C.F. et al. Diferentes suplementos no cultivo in vitro de embriões de pinhão manso. Pesquisa agropecuária brasileira, v.43, n.1, p.9-14, 2008.

VAZQUEZ MOLINA, D.E. et al. Sugar cane buds as an efficient explant for plantlet regeneration. Biologia Plantarum v.49, p.481-485, 2005. Disponível em: <http://springerlink.com/ content/1165h14730u55466/>. Acesso em: 03 set. 2005. 